\title{
Chronic pancreatitis in India: untying the nutritional knot
}

\author{
Pramod Kumar Garg
}

Received: 15 February 2011 / Accepted: 13 April 2011 /Published online: 18 May 2011

(C) Indian Society of Gastroenterology 2011

Nutrition is central to human existence from sustenance of cellular life to powering its myriad functions. Contrasting images of Haitian or Ugandan malnourished children and Westerner obese kids mirror not only the economic reality of a nation but also the propensity to diseases albeit of opposite polarity from Kwashiorkor/Marasmus to metabolic syndrome with equal implications for health outcomes. In addition to specific nutritional deficiency states such as scurvy and rickets, indirect effects of nutrition on human health are of greater importance.

In this context, astute clinical observations in 1960s brought attention to a rather typical form of chronic pancreatitis (CP) in Kerala [1]. The picture of a young malnourished patient with chronic calcific pancreatitis and diabetes evoked much interest. Since one of its most peculiar features was malnutrition (undernutrition), it was soon implicated in its etiopathogenesis. At a time when the basic structure of DNA was just about making the headlines, genetic mutation as the cause of disease was not even on the agenda outside of Mendelian disorders. Malnutrition thus made the cut being the striking clinical feature. Since the disease was reported mainly from tropical countries, which ironically were much poorer and undernourished than their temperate counterparts, the term 'tropical pancreatitis' (TP) was coined for want of a more defining terminology.

Protein deficient and high carbohydrate diet was thus implicated in the etiopathogenesis of the thus coined TP. Sandhyamani et al. [2] showed that high carbohydrate and

\section{P. K. Garg $(\bowtie)$}

Department of Gastroenterology,

All India Institute of Medical Sciences,

New Delhi 110 029, India

e-mail: pkgarg@aiims.ac.in low protein diet, either comprising of cornstarch or cassava, resulted in ductal changes with mucoid metaplasia and parenchymal atrophy in an animal model of bonnet monkey. However, pancreatic changes were rather different from those typically seen in CP and the animals predominantly developed vascular and cardiac changes - features not observed in CP patients. Furthermore, severe malnutrition has been shown to result in pancreatic atrophy and insufficiency and not $\mathrm{CP}$ thus disproving the nutritional hypothesis [3]. Since cassava was a staple diet in Kerala, it gained the status of a co-culprit as a logical extension of the nutritional hypothesis. The cassava hypothesis has also been discarded because: (i) cassava consumption was not found as a risk factor in case-control studies including one from Kerala [4], (ii) patients with the TP were reported from areas where cassava was not consumed [5], and (iii) long-term cassava consumption did not produce diabetes or pancreatitis in a rat model [6].

Even though the association of malnutrition with $\mathrm{CP}$ was consistent, not many clinical studies examined the cause and effect relationship. Our group first showed that malnutrition was an effect and not a cause of CP. In a prospective study of 120 patients with idiopathic $\mathrm{CP}$, only $20.6 \%$ were underweight before the onset of the disease while $67 \%$ lost weight following the disease suggesting that malnutrition was an effect and not a cause of CP [5]. A recent study by Sathiaraj et al. [7] has reiterated that malnutrition was not a cause of TP (idiopathic CP) in southern Indian patients as only $15 \%$ patients were malnourished before the onset of disease and $52 \%$ of patients lost weight subsequently. In this issue of the journal, Regunath et al. [8] have further strengthened these observations. In their study of 54 patients, premorbid BMI in 35 patients with TP (idiopathic $\mathrm{CP}$ ) was significantly higher than the BMI in the same patients at presentation 
suggesting that the patients were normally nourished before the onset of disease and lost weight afterwards. The authors did not find any particular cause for undernutrition possibly due to a small sample size and a lack of study of dietary intake of patients. We had found diabetes and intake of higher percentage of calories from proteins as two important causes of malnutrition [5]. Thus, these studies from different centers have largely put to rest any doubt that undernutrition is not a cause of idiopathic CP (TP) in India.

Although data are convincing that malnutrition is not causally related to the etiopathogenesis of $\mathrm{CP}$, it is possible that malnutrition modulated the phenotypic expression of the disease. The consistent observations made during the 1960s and 70s cannot simply be brushed aside. At that time, severe protein calorie deficiency resulted in a malnourished patient, early pancreatic atrophy and consequent endocrine failure leading to diabetes. Similarly, absence of steatorrhea and ketosis can be explained by substrate deficiency due to malnutrition. Over the past 3-4 decades, there has been a definite change in the phenotypic profile of idiopathic CP in India: the age at onset has shifted from adolescence to mid twenties, the BMI of most patients is no longer below normal (i.e. $<18.5$ ), diabetes is seen in only a third to a half of patients as opposed to $90 \%$ reported earlier, and the longevity of patients has increased [9-11]. How does one reconcile with these emerging trends in the disease phenotype? Economic gains by the country during the past four decades have resulted in substantial decline in poverty and malnutrition. In Kerala for example, the headcount index for poverty has declined from $59.8 \%$ in 1973-74 to $12.7 \%$ in $1999-2000$ [12]. The net state GDP was Rs. 1457 crore $(\sim 320$ million) and the per capita GDP was Rs. $665(\sim \$ 15)$ in 1972-73; these figures increased to Rs. 62,557 crore $(\sim 13.75$ billion) and Rs. 23,865 (\$525), respectively in 1999-2000, i.e., an almost 40-fold increase [13]. Improvement in nutrition with growing economy has made the difference to the phenotype of patients with chronic pancreatitis - normal BMI, late presentation, delayed onset of diabetes and better outcomethus making the disease look different. Conventional wisdom will be mistaken if one assumes that the earlier seen variety of $\mathrm{CP}$ in India i.e., TP is disappearing because unlike infectious disease, a disease with strong genetic basis cannot just be wished away. Its phenotype can however, certainly change due to environmental factors. For example, pregnant mice with identical genotype gave birth to offspring of a different coat color when maternal diet was supplemented with methyl donors, an epigenetic effect that lasted in the next generation [14]. The conundrum of $\mathrm{CP}$ and its changing phenotype further exemplifies this phenomenon [11].

If macronutrient and energy deficiency are not etiologically related to the pathogenesis of $\mathrm{CP}$, it is still possible that micronutrient deficiencies might be playing a role. Indeed, micronutrient deficiencies are common and likely to be related to the pathogenesis through oxidative stress. Oxidative stress has been implicated in the pathophysiology of CP [15]. In this issue of the Journal, Girish et al. [16] from Kerala have shown enhanced lipid peroxidation and decreased antioxidant status in both idiopathic CP (TP) and alcoholic CP. The authors have further extended their previous observation that zinc deficiency may have a significant role to play. Zinc deficiency may occur due to pancreatic exocrine insufficiency [17]. Moreover, zincuria has been observed in most cases with pancreatic insufficiency. The authors' suggestion that an early age of onset and rapid course of TP as the reasons for decrease in vitamin $\mathrm{C}$ levels and higher thiobarbituric acid reactive substances (TBARS) is however, conjectural. One of the limitations of this study was subgroup analyses without correcting for multiple comparisons which might have impacted the significance of some of the variables.

From a therapeutic standpoint, malnutrition needs to be treated regardless of whether it is a cause or effect. In a randomized clinical trial, we compared the efficacy of MCT-enriched commercially available food supplements with dietary intervention in the form of counseling for regular home-made food [18]. Both commercial food supplementation and dietary counseling improved the nutritional status with significant and comparable improvements in anthropometric parameters including weight, BMI, lean body mass and subcutaneous fat stores at the end of the 3-month study period. Thus, a balanced home-made adequate calorie diet should be prescribed to these patients. Furthermore, in a randomized controlled trial, antioxidant supplementation was associated with relief in abdominal pain and decrease in oxidative stress, thus supporting the oxidative stress hypothesis [19]. Antioxidants should be prescribed in a proper dose as used in that study with a combination of $0.54 \mathrm{~g}$ ascorbic acid, $9000 \mathrm{IU} \beta$-carotene, $270 \mathrm{IU} \alpha$-tocopherol, $600 \mu \mathrm{g}$ organic selenium and $2 \mathrm{~g}$ methionine per day in divided doses.

The 2 studies in this issue of the Journal from southern India have again emphasized that the clinical profile of TP is much different from that reported earlier and in sync with the idiopathic CP reported elsewhere [20]. The Manipal group diagnosed TP by excluding other causes of $\mathrm{CP}$, suggesting that this was idiopathic CP. The Kochi study also used the term tropical pancreatitis while referring to a study in which the majority of patients were akin to idiopathic CP [21]. The idea that this type of CP is special arose from the earlier observations of severe malnutrition, diabetes and marked calcification-features much mellowed and modified now. A possibly higher prevalence and a rapidly progressive course in a few patients notwithstanding, there is nothing much to suggest that 
idiopathic CP in India is a different disease. Further insight into the pathogenesis with mutations in SPINK1 and CFTR genes has shifted the focus to a molecular level for further elucidation of the pathobiomechanism of the disease [11]. In such a scenario, sticking to an old terminology i.e. 'tropical' is an oddity especially since there is nothing to suggest any influence of geographic location either on its pathogenesis, phenotype or disease behaviour [22].

"All is flux, nothing remains the same" (Heraclitus).

\section{References}

1. Geevarghese PJ. Pancreatic diabetes: a clinicopathological study of growth onset diabetes with pancreatic calculi. Bombay: Popular Prakashan; 1968.

2. Sandhyamani S, Vijayakumari A, Nair MB. Bonnet monkey model for pancreatic changes in induced malnutrition. Pancreas. 1999; 18:84-95.

3. Brooks SE, Golden MH. The exocrine pancreas in kwashiorkor and marasmus. Light and electron microscopy. West Indian Med J. 1992;41:56-60.

4. Narendranathan M, Cheriyan A. Lack of association between cassava consumption and tropical pancreatitis syndrome. J Gastroenterol Hepatol. 1994;9:282-5.

5. Midha S, Singh N, Sachdev V, Tandon RK, Joshi YK, Garg PK. Cause and effect relationship of malnutrition with idiopathic chronic pancreatitis: prospective case-control study. J Gastroenterol Hepatol. 2008;23:1378-83.

6. Mathangi DC, Deepa R, Mohan V, Govindaranjan M, Namasivayam A. Long-term ingestion of cassava (tapioca) does not produce diabetes or pancreatitis in the rat model. Int J Pancreatol. 2000;27:203-8.

7. Sathiaraj E, Gupta S, Chutke M, et al. Malnutrition is not an etiological factor in the development of tropical pancreatitis - a case-control study of southern Indian patients. Trop Gastroenterol. 2010;31:169-74.

8. Regunath H, Shivakumar BM, Kurien A, Satyamoorthy K, Pai CG. Anthropometric measurements of nutritional status in chronic pancreatitis in India: comparison of tropical and alcoholic pancreatitis. Indian J Gastroenterol. 2011;30: doi:10.1007/s12664-011-0093-9.
9. Midha S, Khajuria R, Shastri S, Kabra M, Garg PK. Idiopathic chronic pancreatitis in India: phenotypic characterization and strong genetic susceptibility due to SPINK1 and CFTR gene mutations. Gut. 2010;59:800-7.

10. Bhasin DK, Singh G, Rana SS, et al. Clinical profile of idiopathic chronic pancreatitis in north India. Clin Gastroenterol Hepatol. 2009;7:594-9.

11. Balakrishnan V, Nair P, Radhakrishnan L, Narayanan VA. Tropical pancreatitis - a distinct entity, or merely a type of chronic pancreatitis? Indian J Gastroenterol. 2006;25:74-81.

12. Human Development Report. Published by State Planning Board, Government of Kerala; 2005. p. 49.

13. Kannan KP, Hari KS. Kerala's Gulf connection. Emigration, remittances and their macroeconomic impact 1972-2000, Working paper no. 328, 2002. (http://www.cds.edu/download files/328.pdf).

14. Cropley JE, Suter CM, Beckman KB, Martin DI. Germ-line epigenetic modification of the murine $\mathrm{A}$ vy allele by nutritional supplementation. Proc Natl Acad Sci USA. 2006;103:17308-12.

15. Tandon RK, Garg PK. Oxidative stress in chronic pancreatitis: Pathophysiological relevance and management. Antioxid Redox Signal. 2011 (in press).

16. Girish BN, Rajesh G, Vaidyanathan K, Balakrishnan V. Assessment of oxidative status in chronic pancreatitis and its relation with zinc status. Indian J Gastroenterol. 2011;30: doi:10.1007/s12664-011-0094-8.

17. Dutta SK, Procaccino F, Aamodt R. Zinc metabolism in patients with exocrine pancreatic insufficiency. J Am Coll Nutr. 1998; 17:556-63.

18. Singh S, Midha S, Singh N, et al. Dietary counseling versus dietary supplements for malnutrition in $\mathrm{CP}$ : a randomized controlled trial. Clin Gastroenterol Hepatol. 2008;6:353-9.

19. Bhardwaj P, Garg PK, Maulik SK, Saraya A, Tandon RK, Acharya SK. A randomized controlled trial of antioxidant supplementation for pain relief in patients with chronic pancreatitis. Gastroenterology. 2009;136:149-59.

20. Joergensen $M$, Brusgaard $K$, Crüger DG, Gerdes AM, de Muckadell OBS. Incidence, prevalence, etiology, and prognosis of first-time chronic pancreatitis in young patients: a nationwide cohort study. Dig Dis Sci. 2010;55:2988-98.

21. Balakrishnan V, Unnikrishnan AG, Thomas V, et al. Chronic pancreatitis: a prospective nationwide study of 1,086 subjects from India. JOP. 2008;9:593-600.

22. Garg PK, Midha S, Khajuria R, Kabra M. Authors' reply. Gut. 2010, Nov. 29 doi:10.1136/gut.2010.228379. 